\title{
Der allgegenwärtige Blick des Richters. Juridische Evidenz bei Albrecht Dürer und Lucas Cranach d. A..
}

Claudia Blümle

Im Englischen steht evidence für den Beweis, der während des Gerichtsverfahrens erbracht werden muss. Dieser Sprachgebrauch macht deutlich, wie stark die juridische Praxis bis heute von einer Rhetorik des Sehens bestimmt ist. ${ }^{1}$ In der Verschränkung von Reden und Sehen wird das Gericht als ein theatralischer Raum erkennbar, in dem Beweisführung auf den Fluchtpunkt einer unmittelbaren Sichtbarkeit verwiesen ist. Dabei verwandelt sich der Gerichtsraum in eine Szene, in der sich die Wahrheitsfindung unter dem richterlichen Blick ereignet. Die folgenden Überlegungen befassen sich mit den historischen Anfängen dieser Konstellation im 15. Jahrhundert, wobei anhand des Kupferstichs Sol Iustitiae von Albrecht Dürer sowie des Gemäldes Das Urteil Salomonis von Lucas Cranach d. Ä. und seiner Werkstatt gezeigt werden soll, dass Bilder in maßgeblicher Weise an der Herausbildung dieses Raums juridischer Sichtbarkeit beteiligt waren.

\section{I}

Der um 1498/99 datierte Kupferstich Sol Iustitiae gehört nach Erwin Panofsky »trotz seines kleinen Maßstabes $[79 \times 107 \mathrm{~mm}]$ zu Dürers eindrucksvollsten Schöpfungen «. ${ }^{2}$ [Abb. 1] Das Bild zeigt einen grimmig blickenden Löwen, auf dessen Rücken eine männliche Figur mit weit aufgerissenen Augen sitzt. Eine aus dem Fleisch herausragende Flammenmaske umrahmt die schwarzen Punkte seiner Pupillen und die kreisrunden Augen, deren Ausstrahlung mittels Strahlenkranz und doppelten Nimbus verstärkt wird. Anhand dieser aus drei Flammenzungen bestehenden Maske, die auf eigentümliche Weise mit der Nase und den durch mehrere Linien umrissenen Augen verwachsen ist, 


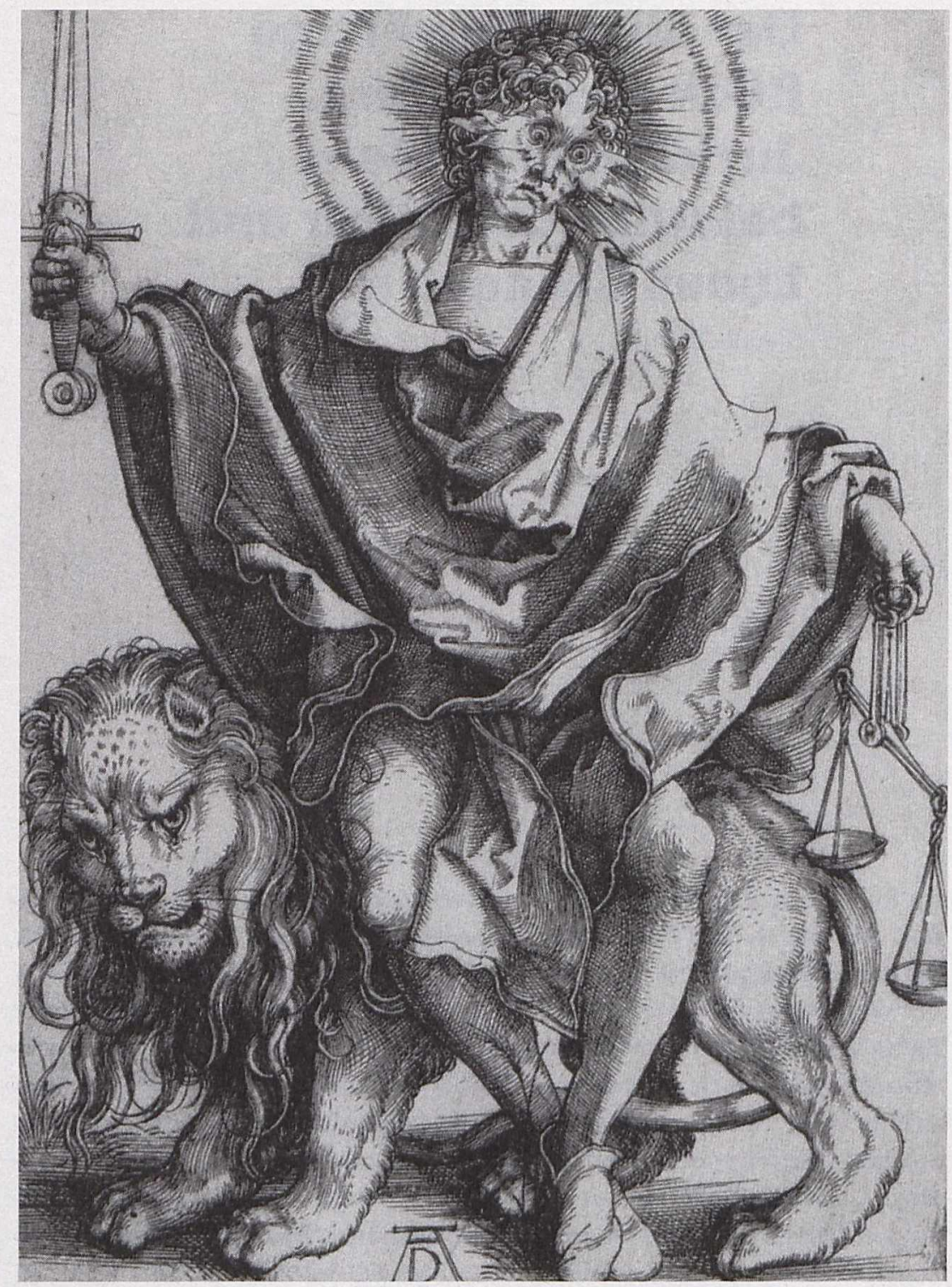

1 Albrecht Dürer, Sol lustitiae, um 1498/99. thematisiert der Kupferstich die Tätigkeit des Schauens, die überdies in der direkten Konfrontation des Betrachters mit dem grimmigen Löwenblick besteht. Da die sitzende Person den Kopf nach rechts wendet, scheint ihre Blickrichtung einen außerhalb des Bildes befindlichen Punkt zu fokussieren. Von der Fußspitze und dem Grashalm über den Zipfel der Stola bis zum strahlenden Kopf entsteht innerhalb dieser männlichen Figur, die fast den gesamten Raum des Bildes einnimmt, eine zentrierte Vertikalität, die das Bild in zwei Hälften teilt und dadurch formal den Aspekt des Gleichgewichts und Ungleichgewichts in die Komposition überführt. Die halbkreisförmige, reich drapierte Stola betont die leichte Diagonale der Armbewegung, die ein Ungleichgewicht zwischen dem parallel zum Bildrand gerade nach oben weisenden Schwert und der leeren Waage darstellt, deren vordere Schale nach unten geneigt ist. Diese 
Thematisierung des Urteilens, die sich, verbunden mit derjenigen des Sehens, auf unheimliche Weise in der Darstellung von Tier und Flammenmaske manifestiert, steht in Verbindung mit einer äußerst komplexen Ikonographie, die heidnisch-antike, astrologische, christliche und juridische Bezüge aufweist.

Der im antiken Sonnenkult verehrte, griechisch Helios und römisch Sol genannte Sonnengott wurde auf Münzen, Grabsteinen oder Tempeln durch einen Heiligenschein aus Lichtstrahlen gekennzeichnet. [Abb. 2] Dieser konnte in zwei geometrisch unterschiedlichen Formen in Erscheinung treten: einerseits als Nimbus in Form einer runden Scheibe oder eines Kreises, andererseits als Strahlenkranz »in Form radial vom Kopf ausgehender Strahlen.$^{3}$ Der Nimbus, der ursprünglich in Anlehnung an die Sonne für die solare Lichtgottheit reserviert war, wurde bald auf Halbgötter, Heroen oder Personifikationen 


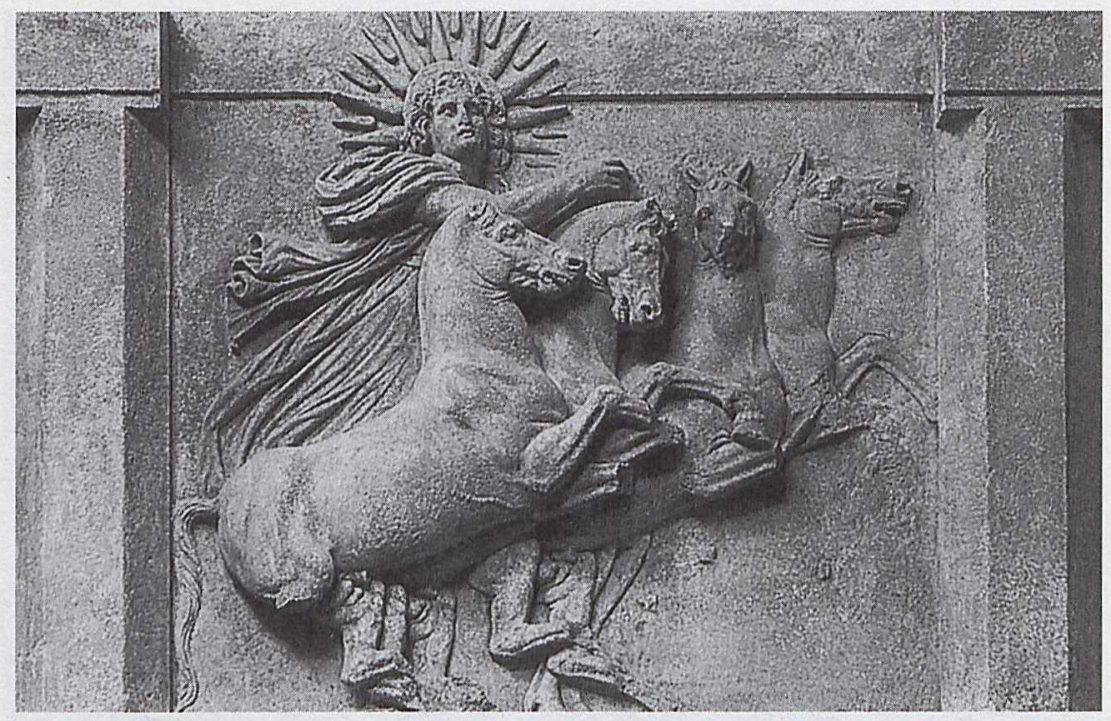

2 Helios, Metope vom Athena-Tempel in Troja, um 390 v. Chr. übertragen, der an der Sonne entwickelte Strahlenkranz hingegen setzte sich besonders in Herrscherdarstellungen durch. In Dürers Kupferstich sind diese beiden Typen des Heiligenscheins vereint: Der dunkel schraffierte Strahlenkranz wird von einem kreisförmigen Nimbus, der in kleinen Parallelstrichen und doppelt gezeichnet ist, umrahmt. [Abb. 1] Wie die Darstellung Helios reitet auf dem Tierkreisbild des Löwen zu erkennen gibt, [Abb.3] geht die Ikonographie der auf dem Rücken eines Löwen sitzenden Gestalt neben der antiken Bildtradition der Sol Iustitiae ${ }^{4}$ auf einen astrologischen Typus zurück. Diese Buchillustration, mit der Friedrich Teja Bach das Dürer-Bild vergleicht, ist überdies hinsichtlich der Darstellung des Kopfes aufschlussreich, da sie den aus Dreieckselementen gebildeten Strahlenkranz ebenfalls mit dem kreisförmigen Nimbus verbindet. Teja Bach rückt Dürers Kupferstich Sol Iustitiae, [Abb. 1] der bis dahin als Einzelblatt betrachtet wurde, in einen größeren astrologischen Zusammenhang, indem er zeigt, dass dieser mit der Luna als Bildpaar den Abschluss der fünf Planetenbilder bilden könnte. ${ }^{5}$

Zur antiken und astrologischen Ikonographie tritt eine christliche Lesart hinzu, die visuell und aufgrund der fehlenden Attribute weniger offensichtlich ist. Es war Erwin Panofskys Verdienst, die allegorische Bilderfindung, "die christliche und heidnisch-antike Vorstellungen, Planetengottheit und christliches Gottesbild verbindet,$^{6}{ }^{6}$ zu entschlüsseln. Diese spätantike Tradition $^{7}$ geht auf die Übereinstimmung des Festtages zu Ehren Sols am 25. Dezember mit der christlichen Weihnachtsfeier zurück. ${ }^{8}$ So wurde auch Sol invictus als unbesiegter Sonnengott mit der Auferstehung Christi in Verbindung gebracht. ${ }^{9}$ Seit dem 2. Jahrhundert gehört die biblische Formel der Sol Iustitiae zur kirchlichen Rhetorik, ${ }^{10}$ die sich auf den Propheten Maleachi stützt: »Euch aber, die ihr meinen Namen fürchtet, soll aufgehen die Sonne der Gerechtigkeit«. ${ }^{11}$ Nach Panofsky hatten die Kirchenväter dank dieser Zeilen Sol invictus, den höchsten Gott des römischen Reiches, in eine Sol Iustitiae umwandeln können, und diese »kühne Gleichung, wohl geeignet, die Furcht des Gerichts in die Herzen der Gläubigen zu senken, überlebte mehr als ein Jahrtausend «. ${ }^{12}$ 


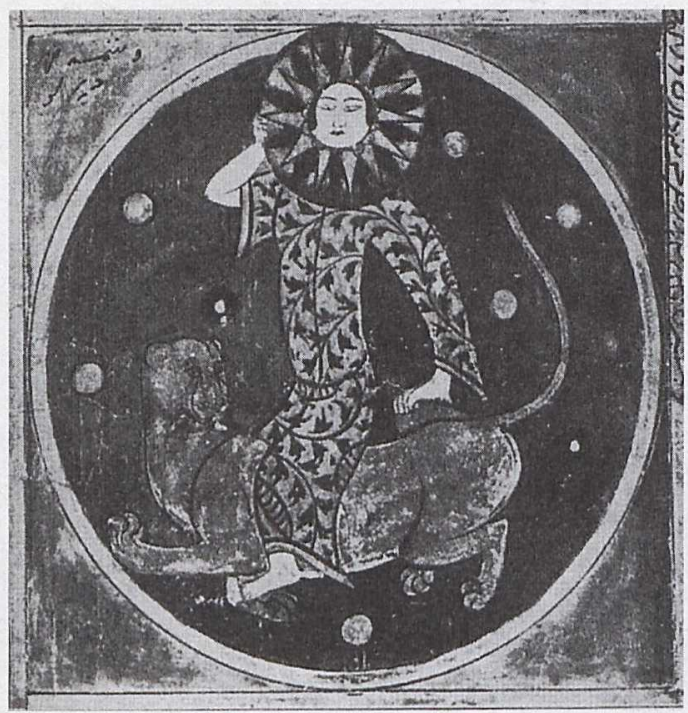

Dürers direkte Quelle war wahrscheinlich das vom Benediktiner Petrus Berchorius verfasste Werk Repertorium morale, eines der meistgelesenen theologischen Handbücher des späteren Mittelalters. Anton Koberger, der Taufpate Tierkreisbild des Löwen, Liber Bohan, Cod. Bodl. Or. 133. Albrecht Dürers, gab neben der Gesamtausgabe des Corpus Iuris Civiles des Justinian, der Schedelschen Weltchronik und dem im Jahre 1484 erstmals gedruckten Nürnberger Stadtrecht ${ }^{13} 1489$ auch dieses Handbuch heraus, in dem folgende Passage zu lesen steht:

"Vor allem aber sage ich von jener Sonne [der Gerechtigkeit], dass sie in Flammen [inflammatus] stehend sein wird, wenn sie die Menschheit richten wird im Gericht, so sie selbst hart und streng sein wird, auf dass sie sich zeigt, wie es heisst. In der Blutröte wird diese dann ganz glühend und schrecklich sein in ihrer Gerechtigkeit und Strenge. Denn wie die Sonne am heissesten ist, wenn sie in der Mitte des Himmels steht, im Zenit, so auch Christus, wenn er inmitten des Himmels und der Erden im Gericht erscheinen wird [...], und dann in der Strenge und Gerechtigkeit glühen und die Sünder schrecklich und hart verdammen wird. Was gut dargestellt ist in Offb 19 wo es heisst, dass der Sonne gegeben wird die Menschen mit Hitze und Feuer heimzusuchen. [...] Denn wie die Sonne im Sommer, wenn sie im Löwen steht, die Pflanzen verbrennt, die der Frühling dann wiederbelebt, so wird Christus in der Hitze des Gerichts erscheinen als ein grimmiger und löwengleicher Mann [homo ferus et leoninus] und die Sünder verwelken lassen und das Glück der Menschen zerstören. $\ll^{14}$

Ausgehend von diesem im Text entworfenen Christusbild, das den Gottessohn als Löwen und Richter beschreibt, ist es möglich, die sitzende Figur in Dürers Stich christlich zu lesen. Folgt man der dem Text entnommenen apokalyptischen Deutung, würde es sich bei der männlichen Gestalt mit dem Flammenblick um Christus als Weltenrichter handeln. Diese Verbindung zwischen antikem Sonnenglauben und Christentum wird zu Dürers Zeiten 


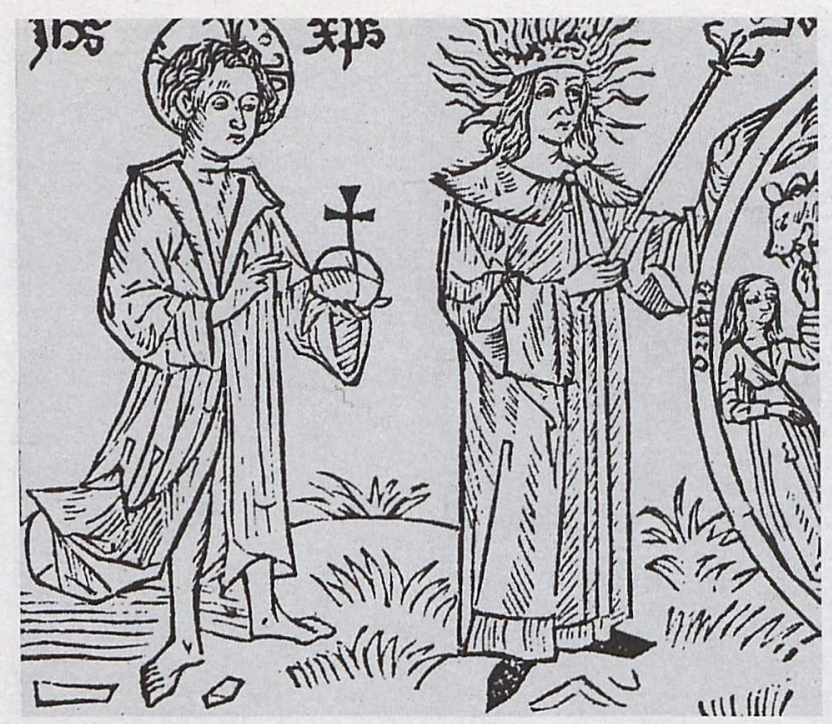

4 Johannes Virdung, Christus und Sol, 1495 (Detail). mehrmals erläutert, so bei Marsilio Ficino, der die platonische Vorstellung von der Sonne und die Sonnenhymnen der Pythagoräer mit dem Psalmwort »in der Sonne hat er sein Zelt errichtet $\aleph^{15}$ verknüpft. Auch dürfte um 1500 allgemein Ficinos Bemerkung aus dem Libellus de Sole gelten: „Wer sieht nicht, dass die Sonne in der Welt Gottes Bild und Stellvertreter ist. « ${ }^{16}$ Neben Ficino ist auch bei Berchorius die Wesensgleichheit von Sol als antikem Sonnengott und Christus als Weltenrichter ausführlich belegt. ${ }^{17}$

\section{II}

Im Holzschnitt des Lateinischen Almanachs für das Jahr 1495 von Johannes Virdung wird die Verbindung Sol-Christus deutlich. [Abb.4] Dabei wird Christus mit einem Kreuznimbus und Sol mit einem flammenden Strahlenkranz sowie einer Strahlenkrone dargestellt. Beide Figuren, die bei Virdung getrennt nebeneinander stehen, sind in Dürers Kupferstich übereinander gelagert und zu einer Figur vereint. Als Vorläufer der bildlichen Beziehung SolChristus gelten zahlreiche römische Münzen, in denen der jeweilige Kaiser-an prominenter Stelle stehen Probus, Aurelius und Konstantin-im Profil neben dem Sonnengott mit Strahlenkrone erscheint und sich physiognomisch an diesen angleicht. [Abb.5] Anhand des Phänomens der Doppelbildnisse konnte Ernst Kantorowicz zeigen, dass nur Dank dieser bildlichen Wirksamkeit der geminatio, einer »Verdoppelung « im Sinne von Kantorowicz ${ }^{18}$ der Kaiser zur persona geminata $-»$ menschlich von Natur, göttlich durch die Gnade ${ }^{19}$-gemacht werden konnte.

Die am Beispiel römischer Münzen aus dem 3. und 4. Jahrhundert erläuterte geminatio wird in der christlichen Hermeneutik typologisch gewendet. Nach Friedrich Ohly nimmt die Typologie, die ihren Ort in der Auslegung der Bibel hat, in ihrer deutenden Denkform ebenfalls Bezug auf außerbiblische Gegenstände aus der antiken Philosophie, Dichtung oder historischen Profangeschichten. ${ }^{20}$ Als christliche Deutungslehre, die auf diese Weise dennoch zu einer antiken Überlieferung beigetragen hat, allegorisiert die Typologie nicht 


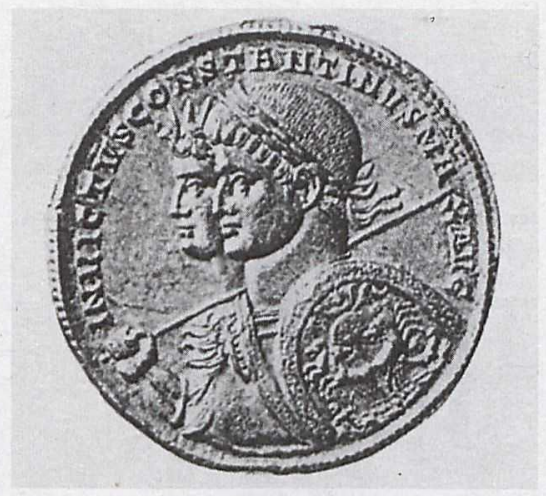

nur Odysseus, Apollo, Prometheus, Augustus, Platon und andere Gestalten, sondern sieht und liest in ihnen Präfigurationen Christi. ${ }^{21}$ Diese Denkweise manifestiert sich in der bildenden Kunst als ein System von Ähnlichkeiten. 5 Doppelprofil von Konstantin und Sol invictus, Gold-Solidus. "Eine das Gemeinsame über das Unterscheidende hebende und bis zur gegenseitigen Durchdringung von Typus und Antitypus gehende Annäherung beider Seiten durch Assimilationen ${ }^{22}$ ist dabei in der bildenden Kunst so geläufig, »dass Typus und Antitypus im Erscheinungsbild nahezu zusammenfallen. ${ }^{23}$ Eine bekannte Reihe von Gemälden und Zeichnungen Leonardo da Vincis, die Johannes den Täufer und Bacchus zusammenführen, verdeutlichen dieses Phänomen. Während das Gemälde von 1509 aus dem Louvre eindeutig Johannes den Täufer zeigt, erhält in der Zeichnung Johannes-Bacchus von 1513 die männliche Figur aufgrund ihrer antikisierenden Nacktheit und den Baumkronen, die ihr Angesicht umhüllen, Elemente eines Bacchus, um schließlich im Gemälde von 1513-15 dominanter hervorzutreten: Die Figur ist mit einem Leopardenfell und einem Weinblätterkranz im Haar geschmückt und das Kreuzzeichen am Stab verschwunden. ${ }^{24}$ Leonardo da Vinci gibt einen antiken und einen biblischen Typus »so ineins zu sehen, dass beide vor einem nicht geistig schauenden Auge ineinander sich verbergen. ${ }^{25}$ Die Verschmelzung von Alt und Neu, von Außerbiblischem und Biblischem bezeichnet Ohly als »Ineinanderschau ${ }^{26}$ Diese ist folglich nicht nur ikonographisch anhand deutbarer Attribute, Kennzeichen oder Symbole, sondern auch aufgrund der spezifischen Wirksamkeit des Bildes möglich, die darin beruht, Elemente, die geistig getrennt oder linear gelesen werden, gleichzeitig wahrzunehmen. Eine solche Zusammenschau nennt Panofsky in Anlehnung an Lucan ein numen mixtum, ${ }^{27}$ das heißt eine aus zwei gegensätzlichen Gottheiten zusammengeführte, gemischte Gottheit. Dank Ficino wurde dieser Fachterminus im 15. Jahrhundert wieder entdeckt. Was die Verschmelzung antiker, astrologischer und christlicher Elemente in ein und derselben Figur, hier des Sol-Christus anbelangt, verwendet Dürer ein ähnliches Verfahren. [Abb.1] Dies erweist auch die künstlerische Rezeption der dürerschen Bildererfindung Sol Iustitiae: 
6 Albrecht Dürer, Christus als Weltenrichter mit Schwert und Lilie (Die kleine Passion: Das Jüngste Gericht), 1509/11.

7 Albrecht Dürer, Justitia, 1495.
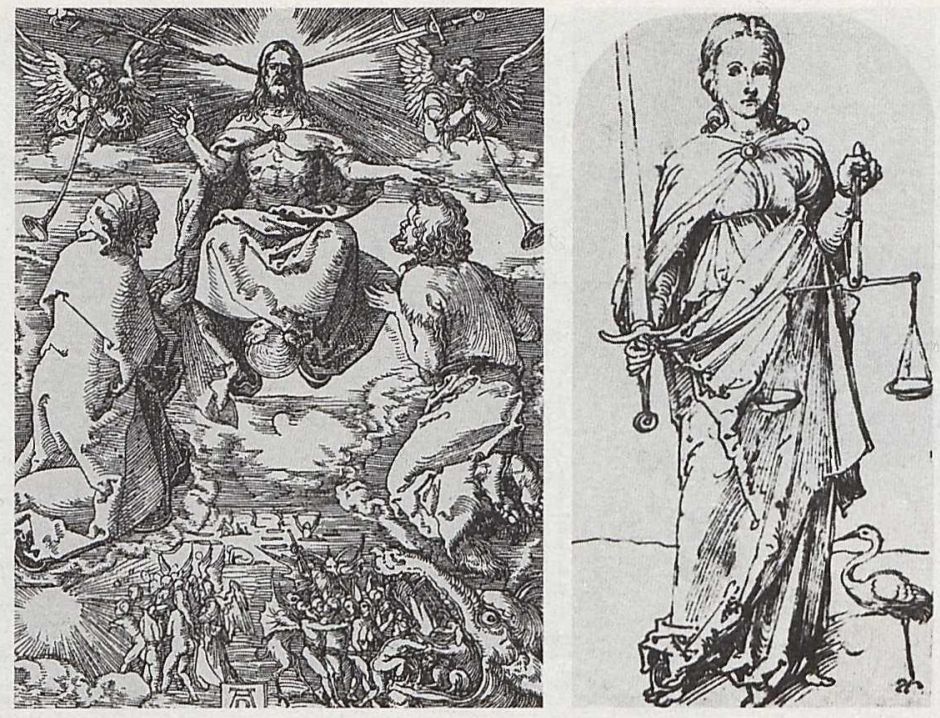

Nicht immer wurde die gesamtbildhafte Verschmelzung der unterschiedlichen Bezüge übernommen, sondern eine Auflösung derselben in ihre Bestandteile angestrebt. Jacob Binks Darstellung der Justitia hat beispielsweise die männliche Figur wieder in eine nackte Frau mit Schwert und Waage in der Hand auf einem Löwen sitzend zurückübersetzt, ohne die christlichen oder astrologischen Elemente aufzunehmen, während umgekehrt der Holzschnitt des Frankfurter Kalenders von 1547 den Sonnengott Sol ohne Bezüge zur Gerechtigkeit in den Vordergrund rückt. ${ }^{28}$

Innerhalb dieser Sol-Christus-Deutung bildet ikonographisch gesehen jedoch die Waage ein Problem, da Christus als Weltenrichter stets mit weißer Lilie und Schwert dargestellt wurde. Auch Dürers Darstellungen des Jüngsten Gerichtes folgen diesen aus dem Johannesevangelium entnommenen christlichen Attributen, [Abb. 6] während Waage und Schwert dem Erzengel Michael oder der weiblichen Personifikation der Justitia [Abb. 7] zugeschrieben werden. ${ }^{29}$ Handelt es sich nun beim Kupferstich Sol Iustitiae [Abb. 1] um ein numen mixtum oder um eine Allegorie? Vermittelt das Bild die Tätigkeit des richterlichen Urteilens als abstrakte Idee oder als heilsgeschichtliches Geschehen? Kurt Rathe betonte 1927, dass es Dürer gelungen sei, die »spätmittelalterliche und antike Auffassung des Gerechtigkeitsthemas zu einem erschütternden Bildgesicht seiner eigensten Prägung zu verschmelzen «, ${ }^{30}$ und auch Thomas Würtenberger stellte den Kupferstich Sol Iustitiae in den umfassenderen Rechtskontext des dürerschen Werkkorpus. ${ }^{31}$ Rainer Schoch verabschiedet hingegen diejenige juristische Lesart, die den Kupferstich lediglich als Justitia oder Nemesis deuten wollte. Teja Bach betont, dass die Bezüge zur weiblichen Personifikation der Gerechtigkeit nicht völlig negiert werden können, doch zeige »Dürers Stich [...] nun freilich nicht Justitia, sondern Christus als >Sonne der Gerechtigkeit $\star .{ }^{32}{ }^{2}$ Innerhalb der Sol-Christus-Typologie ist der juridische Aspekt insofern relevant, als nicht die Attribute, sondern vielmehr der Bezug zur richterlichen Körperhaltung die Figur als christlichen Weltenrichter deutbar machen. Da es sich um einen Zusammenfall antiker, astrologischer, christlicher und allegorischer Ikonographie 

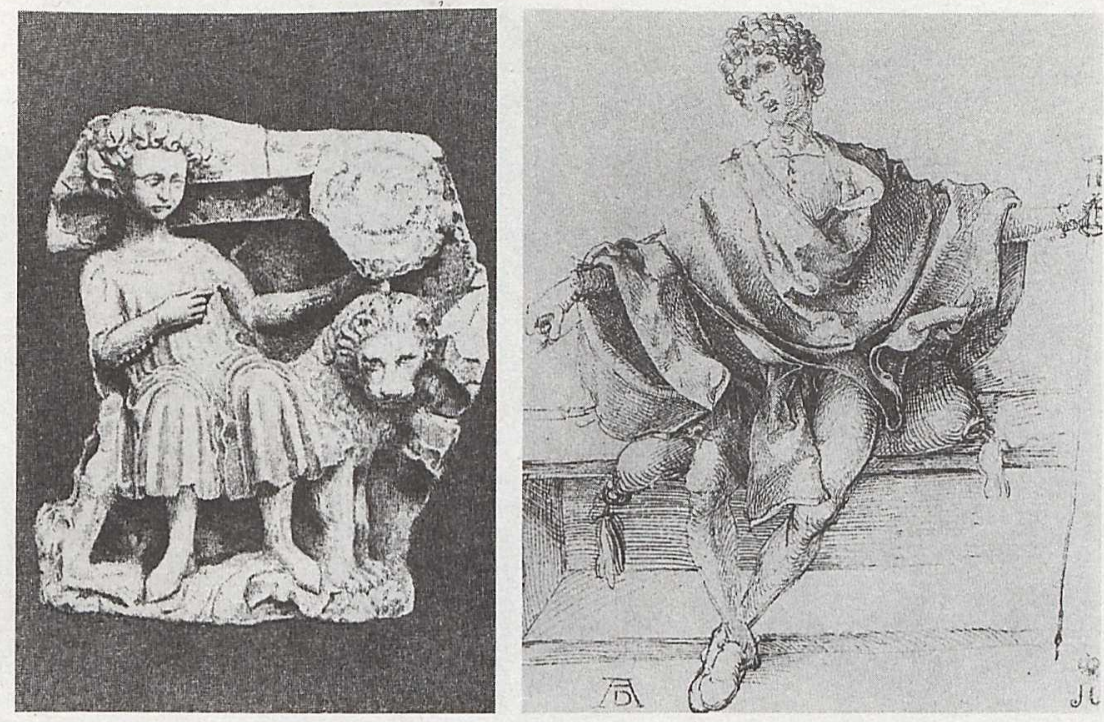

sowie um die Zusammenschau all dieser unterschiedlichen Bereiche in einer Figur handelt, kann jedoch nicht eindeutig entschieden werden, welcher Aspekt dominiert. Bei den Bacchus-Johannes-Darstellungen von da Vinci kann noch in klarer Weise zwischen den zwei Gottheiten unterschieden werden, da diese heilsgeschichtlich zu deuten sind: Bacchus als Präfiguration des Johannes. In dem Moment, in dem jedoch Attribute einer abstrakten Personifikation ins Spiel kommen, stellt sich das Problem komplexer dar. Denn es sind Waage und Schwert, die, wie Schoch betont, »der Darstellung den höheren Abstraktionsgrad der Allegorie $\aleph^{33}$ verleihen.

Neben der ideellen Personifikation der Gerechtigkeit verkompliziert sich die ikonographische Lesart von Sol Iustitiae noch weiter, da nicht zuletzt Bezüge zur richterlichen Beamtentätigkeit vorhanden sind. Dies wird anhand eines Bildvergleichs zwischen der venezianischen Reliefdarstellung Sols [Abb. 8] und Dürers Zeichnung Jüngling mit Stab von 1498 [Abb.9] deutlich. Das um 1415 entstandene Kapitell der Planetengötter am Portikus des Dogenpalastes in Venedig präsentiert Sol als wellenden Lockenkopf, der mit dem Zeigefinger auf eine runde Sonnenscheibe mit doppeltem Kranz weist. Dieses solare Attribut scheint in dem Moment, in dem Dürers Sol Waage und Schwert als Zeichen der Gerechtigkeit in den Händen hält, auf den Nimbus übertragen worden zu sein. Panofsky nimmt an, dass Dürer während seiner Italienreise die venezianische Darstellung des Sonnengottes gesehen hat, die auch leicht seine »Aufmerksamkeit erregt haben konnte: an einem der Kapitelle des Dogenpalastes zu Venedig, der orientalischsten Stadt der westlichen Welt. ${ }^{34}$ Bei diesem Sol-Kapitell [Abb. 8] würde es sich folglich um ein nicht islamisches Beispiel der islamischen Darstellungsweise handeln, die das Tierkreiszeichen des Löwen mit Sol verbindet. [Abb.3] Weiter gilt die Zeichnung Jüngling mit Stab [Abb.9] als Vorstudie zur Sol Iustitiae, die mit den Bildelementen des venezianischen Reliefs in einer Skizze übereinander gelagert wurde. [Abb. 8] Das drapierte Gewand wie auch die runde Lockenfrisur wurde von der Zeichnung übernommen, jedoch nicht das Schwert, das sowohl als Attribut der Justitia als auch des Sonnengottes

8 Sol, Kapitell der Planetengötter, um 1415, Portikus des Dogenplastes in Venedig.

9 Albrecht Dürer, Jüngling mit Waage und Stab, 1498. 


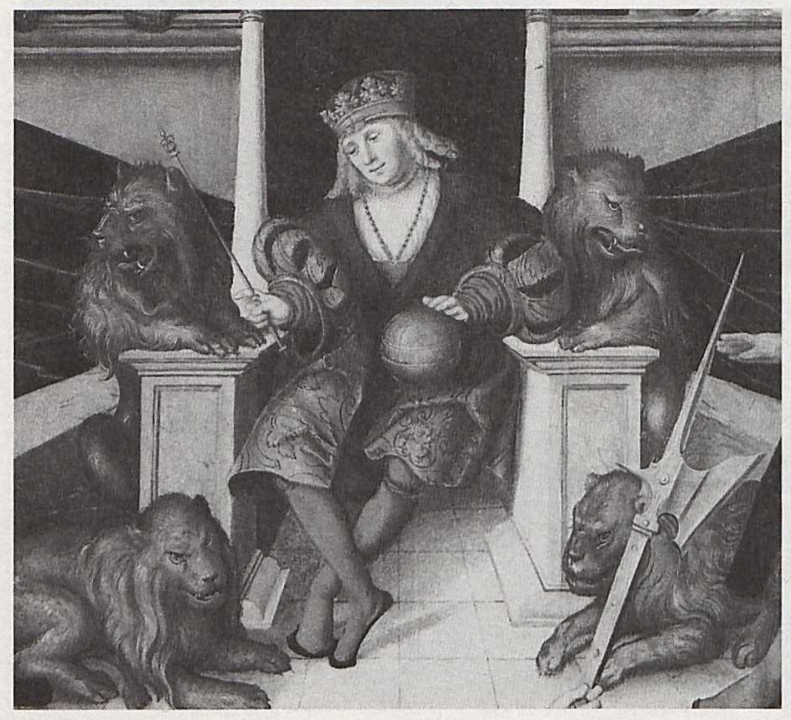

10 Lucas Cranach d. A. und Werkstatt, Das Urteil Salomonis, um 1537 (Detail).
Sol gilt. ${ }^{35}$ Stattdessen hält der Jüngling einen geschälten Stab als »Zeichen der richterlichen Gewalt $\aleph^{36}$ in seiner linken Hand. Schließlich nimmt dieser Jüngling auf einer Holzbank mit gekreuzten Beinen sitzend genau diejenige Körperhaltung ein, "die einen ruhigen und überlegenen Geisteszustand anzeigt « und die »Richtern in alten deutschen Rechtsbüchern tatsächlich vorgeschrieben ${ }^{37}$ wurde. Im Vergleich zu dem venezianischen Sol-Relief erweist sich diese überkreuzte Beinhaltung, die im Kupferstich spiegelverkehrt übernommen wurde, als die maßgebliche Änderung Dürers (vgl. Abb. 1 mit Abb. 8 und 9). Dadurch erhält die Sol Iustitiae neben der ideellen abstrakten Gerechtigkeitsallegorie Justitia [Abb. 7] auch einen Bezug zur weltlichen Rechtspraxis der Zeit.

\section{III}

Die Richter waren im Mittelalter, wie die Arbeiten von Susanne Lepsius deutlich machen, noch davon entlastet, eine eigene Entscheidung treffen zu müssen. Denn «nach der damaligen Überzeugung offenbarte sich durch das göttliche Eingreifen im Gottesurteil und im Eid unmittelbar die >Wahrheit der Sache $\lll .{ }^{38}$ Auf Grundlage der metaphysischen Vorraussetzung, dass Gott selbst auf wunderbare Weise über Rechtsfragen entscheide, konnte »aus Sicht der am Prozess beteiligten Gerichtspersonen ein vollständiges Wissen um Sachverhalt und Recht hergestellt « $^{39}$ werden. Im Hinblick auf dieses Recht der Probe kann deshalb nicht von einem Richter im heutigen Sinne die Rede sein, da er kein urteilender, sondern lediglich ein Kampfrichter war, dessen Aufgabe darin bestand, das Einhalten der Regeln des Parteikampfes, der Eidesleistung oder des Gottesurteils zu überwachen. Mit der Wiederentdeckung und Neuübersetzung des römischen Rechts standen die Richter und die urteilende Gewalt im Spätmittelalter jedoch plötzlich vor dem Problem, selbst urteilen zu müssen. Diese für den Richter neu auftauchende Tätigkeit des Urteilens verbindet sich in Sol Iustitiae [Abb. 1] nicht nur mit den allegorischen Attributen der Gerechtigkeit (Schwert und Waage), sondern auch mit der astrologischen Ikonographie Sols: Von alters her wird auch Sol als Planetengott mit der Funktion des Richters in 


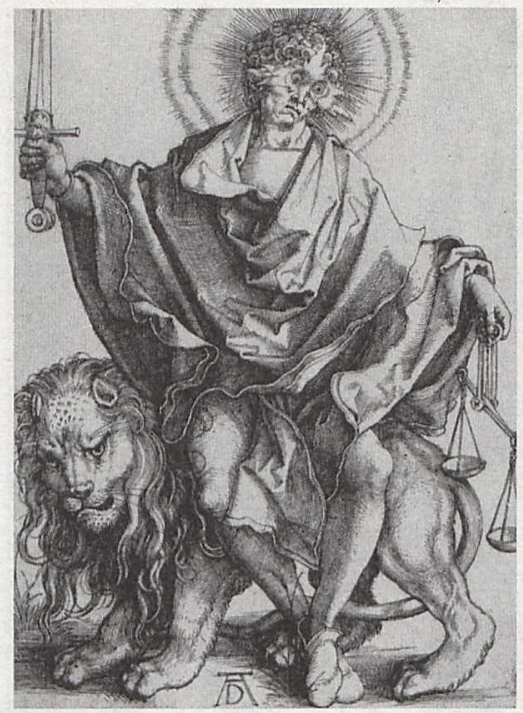

Verbindung gebracht. So begegnet er bei Vettius Valens als Sachverwalter des Urteils, eine Charakterisierung, »die letztlich auf den babylonischen Sonnen11 Albrecht Dürer, gott zurückführt. ${ }^{40}$ Die neue Fokussierung auf den Richter innerhalb eines strafrechtlichen Verfahrens wird in Das Urteil Salomonis von Lucas Cranach d. Ä. und seiner Werkstatt dargestellt und reflektiert. ${ }^{41}$ [Abb. 10 und 12] In dem um 1537 datierten Gemälde, das mehrere Ähnlichkeiten zu Dürers Sol Iustitiae aufweist, ist König Salomon ebenfalls von vier grimmig blickenden Löwen umgeben. Der Löwe verweist hier zunächst auf eine juridische Ikonographie. Vital Huhn konnte zeigen, "dass der Löwe sich aus antik-orientalischen Anschauungen der Macht heraus besonders in Italien schon in der frühchristlichen Zeit als Wahrzeichen des Gerichts entwickelte ${ }^{42}{ }^{42}$ Seit dem karolingischen Reich steht er für das Hochgericht. ${ }^{43}$ Die Säulen, an denen die Todesurteile verlesen wurden, hatten jeweils vier hockende Löwen als Träger, die in Bamberg "Tattermannsäulen " genannt wurden, da man bei ihrem Anblick von einem »datterig «, das heißt von einem Angstzittern erfasst wurde. ${ }^{44}$ Schließlich soll der Richter nach der Soester Rechtsordnung " als ein grisgrimmender Löwe seines Amtes walten «. ${ }^{45}$

Neben dem ikonographischen Bezug des Löwen zum Recht entspricht die Körperhaltung spiegelverkehrt genau derjenigen in Sol Iustitiae. [Abb. 10 und Abb. 11] Nicht nur überschlägt König Salomon in richterlicher Manier seine Beine, sondern sein Kopf neigt sich auch in gleicher Weise zur Seite. Betrachtet man das Gesamtbild Cranachs, so wird deutlich, dass der königliche Richter im Fluchtpunkt des Bildes erhöht thront und sein Kopf sich aufgrund dieser Positionierung nach links wendet, um auf die Szene im Vordergrund blicken zu können. [Abb. 12] Dort erkennt man zwei einander gegenüber komponierte Frauenfiguren: Während die eine neben einem toten Kind kniet, hält die andere stehende Figur ein lebendes Kind in den Armen. Dazwischen befindet sich ein Henker, der nach dem lebenden Kind greift und sein Schwert zieht, um das Kind zu zerteilen. Basierend auf dem ersten Buch der Könige des Alten Testaments wird in Cranachs Gemälde die Geschichte erzählt, wonach König Salomon aufgrund zweier unterschiedlicher Aussagen ein Urteil fällen muss. 


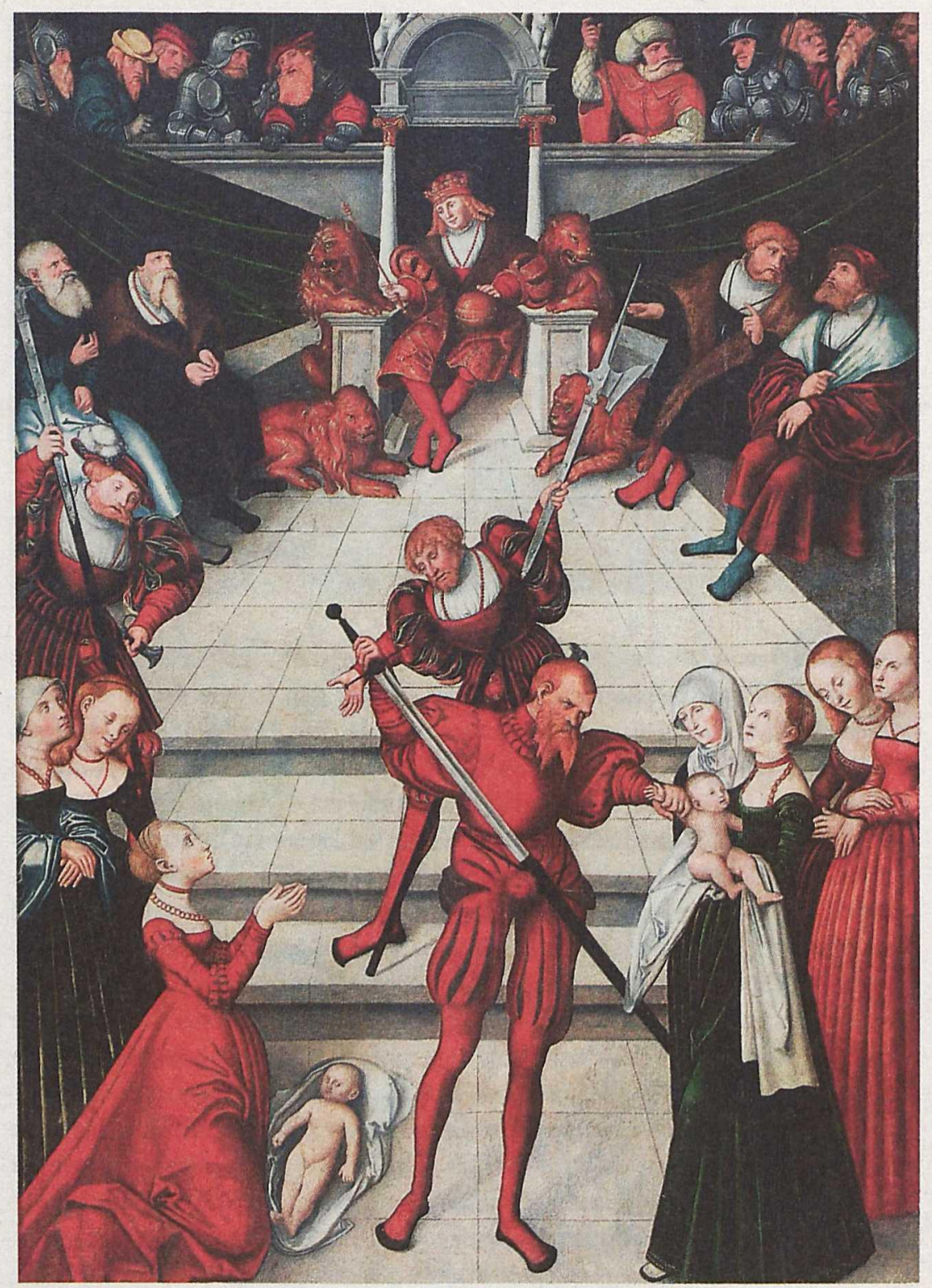

12 Lucas Cranach d. Ä. und Werkstatt, Das Urteil Salomonis, um 1537.
Er ist mit zwei Müttern konfrontiert, die in derselben Nacht ein Kind gebaren, wovon eines starb. Beide Frauen erhoben vor dem Richter den Anspruch, die leibliche Mutter des lebenden Kindes zu sein. Da befahl der König, dass man ihm ein Schwert hole, und er entschied:

"Schneidet das lebende Kind entzwei, und gebt eine Hälfte der einen und eine Hälfte der anderen! $\aleph^{46}$ Daraufhin bat die eine der Frauen darum, das Kind nicht zu töten, während die andere forderte, dass das Kind weder ihr noch der anderen gehören sollte. Da konnte der König feststellen, dass die Erstere die wahre Mutter des Kindes sei und ganz Israel erkannte, »dass die Weisheit Gottes in ihm war, wenn er Recht sprach. « ${ }^{47}$ 
Die Wahl der dargestellten Erzählung steht im Zusammenhang mit der rhetorischen Figur des Exemplums, das im strengen Sinn als ein Beispiel aus der Geschichte zu verstehen ist und im Unterschied zur poetischen Fiktion ( $f a$ bula) mauf der Seite der historia (res gestae) oder des argumentum (res ut gestae) steht . $^{48}$ Diese Unterscheidung ist im 2. Buch der Rhetorik von Aristoteles über das Beweisverfahren und die Beweismittel zu finden, die sich auf Enthymeme oder Beispiele beziehen. Die rhetorische Kunst liegt dabei in der Reduktion des historischen Materials auf einzelne hervorragende Ereignisse oder berühmte Personen ${ }^{49}$ und gerade das Ideal der $»$ Kürze $\aleph^{50}$ oder der Verdichtung $\aleph^{51}$ eines Exemplums rückt diese rhetorische Figur in die Nähe des Bildes. ${ }^{52}$ Wie John D. Lyons gezeigt hat, war die antike und mittelalterliche Assoziation des Exemplums 
mit der Malerei, den Intarsienarbeiten aus Holz oder der rhetorischen imago in der Renaissance vielfach präsent. ${ }^{53}$ Doch nicht nur der metaphorische Vergleich des Exemplums mit einem Bild, sondern die Funktion rückt diese rhetorische Figur in den Bereich einer argumentativ geleiteten Sichtbarkeit. Etymologisch gesehen stammt Exemplum von eximere->herausnehmen`, ‘wegnehmen', sentrücken`. Das Exemplum nimmt etwas heraus und rückt es in einen anderen Zusammenhang. Nach Lyons ist deshalb das Exemplum Teil einer Argumentation als Evidenz im Sinne der lateinischen evidentia: Etwas außerhalb der Sichtbarkeit Liegendes kann gesehen werden (ex und videre). Das Exemplum wird als Schauspiel inszeniert, indem es eine bedeutsame Erscheinung von außerhalb vorführt. Auf das Gemälde von Cranach und seiner Werkstatt bezogen wird diese Struktur besonders in der Architektur und den verschiedenen Beobachterpositionen deutlich. Der exemplarische Fall findet unter dem Blick Salomons in einem theatralen Gerichtsraum statt, während das Publikum weiter oben von einer Empore aus den Streit zwischen den beiden Müttern beobachtet. Diese Szene präsentiert sich auf der vordersten Bildebene wie auf einer Bühne: Vor einem steinernen Stufenabsatz betont der rot bekleidete Henker eine Mittelachse, die mit der Diagonale seines Schwertes durchkreuzt wird. Hinter ihm steht auf einer Stufe ein Soldat, dessen Speer sich diagonal der vertikalen Mittelachse annähert und einen sitzenden Löwen teilweise verdeckt. Die auffallende Symmetrie des Gemäldes kulminiert in der Figur des königlichen Richters, der im Hintergrund auf einem mit zwei weißen Säulen geschmückten Thron sitzt. Die schwarzen drapierten Vorhänge und die steinernen Sitzbänke zur linken und rechten Seite des Thrones verstärken die steile zentralperspektivische Konstruktion der Bühne. Innerhalb dieses in sich geschlossenen Raumes tritt der richterliche Blick in den Hintergrund, während die Szene als Ort der reinen Sichtbarkeit in den Vordergrund des Gemäldes rückt. Diese architektonisch bedingte Blickkonstellation im Bild weist eine auffällige Nähe zu derjenigen des Renaissancetheaters auf, das, wie Hans-Christian von Herrmann deutlich macht, mittels Perspektive, Vorhängen und Beleuchtungseffekten eine Szene herstellt, so dass »die von Aristoteles formulierte Einheit des Dramas nun ausdrücklich als Einheit eines durch einen einzigen Blick konstituierten Schauplatzes « ${ }^{54}$ verstanden werden kann. Diese durch reinen singulären Blick konstituierte Szene perspektiviert das Geschehen auf eine einzige Position, die im Theater der König und im Gerichtsraum der Richter als herausgehobener Zuschauer und Beobachter einnimmt. Im Gemälde Cranachs betonen die graue Emporenwand sowie die Trennung des Richters vom Publikum, das nach hinten auf die Empore gerückt ist, die Hervorhebung eines einzigen souveränen Augpunktes auf der Bühne; besonders auch, weil dieser souveräne Augpunkt mit dem perspektivischen Fluchtpunkt zusammenfällt.

Cranachs Gemälde zeigt, wie das Gericht zur Szene wird. Gottesurteile, Parteikämpfe oder Eidesleistungen besaßen wie die Kreisanordnung im mittelalterlichen Theater keine Szene in dem Sinne, dass ein umgrenzter Raum von einem einzigen souveränen Augpunkt aus beobachtet wird. Stattdessen konnte das im Kreis angeordnete Publikum die rechtlichen Schauspiele von verschiedenen Positionen aus beobachten und gemeinsam mit dem Richter die Einhaltung der Regeln überwachen. In dem Moment, in dem nicht 
mehr Gott, sondern der Richter das Urteil fällen muss, bedarf es während des Gerichtsverfahrens eines zentralen szenischen Ortes im Gerichtsraum, innerhalb dessen sich das Geschehen ereignen soll. Die Szene wird daher der neue Schauplatz einer nicht mehr theologischen Wahrheit. Fortan steht das Publikum hinter dem souveränen richterlichen Blick, um im selben Zug an diesem teilzunehmen. Cranachs theatrale Darstellung des Königssaals als Raum des Hochgerichts setzt rechtshistorisch zugleich eine antike Tradition fort. Vor der Teilung der antiken runden und geschlossenen Rennbahn in eine Bühne als Szene bestand eine unmittelbare Verbindung zwischen dem antikem Theater und der Rechtssprechung: »Das Gericht wird zunächst am selben Ort aufgeführt wie die Tragödie, und es ist kein Zufall, dass es sich in dem Moment davon löst, als die Tragödie mit der Skene ihren entscheidenden Umbau erfuhr. ${ }^{55}$ Mit der Wiederentdeckung des antiken Theaters in der Renaissance wird nun das Gericht mittels der Szene wieder zu einem Theater. Entscheidend ist dabei die architektonisch entwickelte Unterteilung in Schauspieler und Publikum, in Aktive und Passive, in Bewegende und Zuschauende, wie sie im Gemälde Cranachs gezeigt wird. Denn die Frage der Entscheidung und des Urteils, mit der die Richter in dieser Zeit konfrontiert waren, ist an diese theatrale Unterscheidung gebunden: »Die, die zusehen, können auch entscheiden. Distanznehmen, Sicht und Einsicht, Einsicht und Entscheidung bilden eine verkettete Reihe, an deren Ende das auf sich gestellte, reflexive Sich-Entscheiden stehen wird. ${ }^{56}$ Erst im Spätmittelalter ist der Blick des Richters für die gerichtliche Ermittlung von Wahrheit maßgeblich geworden. Da er an Stelle Gottes Urteile fällt, muss er auch einen entsprechend göttlichen Blick einnehmen, um den Ort einer absoluten Wahrheit zu besetzen.

\section{IV}

Mit dem Blick des Richters und dem Volk als Publikum auf der Empore werden in Cranachs Gemälde diejenigen Beobachterpositionen präsentiert, die das ganze Bild in ein `Theater auf dem Theater überführen. [Abb. 12] Während die Szene als Ort der reinen Sichtbarkeit nach vorne rückt, bildet der Blick des Richters im Fluchtpunkt der zentralperspektivischen Konstruktion das Zentrum des Bildes. Der Blick des Richters mündet jedoch nicht nur in den Fluchtpunkt, sondern konstituiert im selben Zug auch den Ausgangspunkt der Szene. Erst wenn der Richter im Gerichtsraum die Szene überblickt, kann das Publikum, wie es hinter der Tribüne dargestellt ist, am Wahrheitsgeschehen teilhaben. Erst in dem Moment, in dem der Richter als Souverän des juridischen Theaters in seiner erhöhten Übersicht den Zusammenhang des Geschehens auf der Szene garantiert und auf diese Szene schaut, kann ein Wahrheitsgeschehen stattfinden, und erst dann kann das Publikum, wie es hinter der Tribüne dargestellt ist, an diesem Ereignis teilnehmen. Ohne richterlichen Blick über die Szene, der während des Gerichtsverfahrens stets gegenwärtig sein muss, kann das Gericht kein Ort der Wahrheitsfindung sein.

Dürers Sol Iustitiae [Abb.1 und 11] überführt genau diese Bedingungen juridischer Evidenz in ein Bild, indem die mit den Attributen der Gerechtigkeit versehene und auf einem Löwen sitzende männliche Richterfigur Dürers den Glanz eines Heiligenscheines erhält. Aufgrund der Entwicklung 


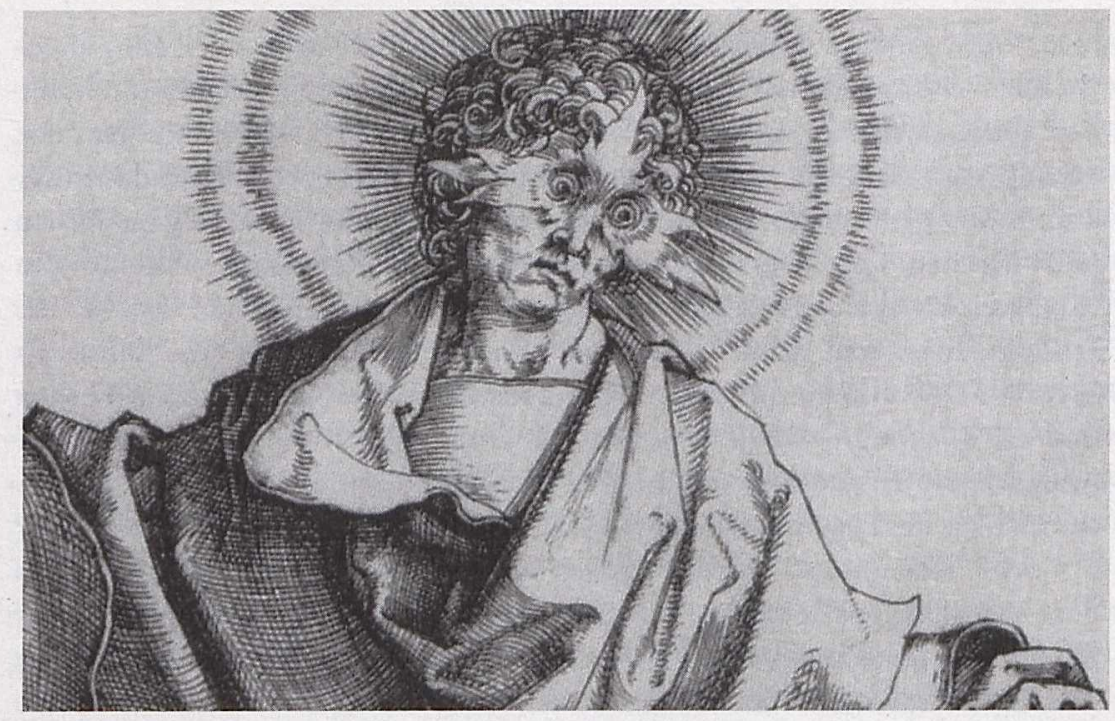

13 Albrecht Dürer, Sol lustitiae, um $1498 / 99$ (Detail). von Nimbus und Strahlenkranz des antiken Sonnengottes hin zu einer christlichen Verwendung kann hinsichtlich des Heiligenscheins nicht klar zwischen Sol und Christus unterschieden werden. Der Lichtglanz der feurigen Sonnengottheit, dessen solare Konnotation mit der Zeit »zugunsten eines umfassenderen Lichtcharakters etwas in den Hintergrund ${ }^{57}$ trat und auf Christus übertragen wurde, wird bei Dürer nun in Verbindung mit dem Sehen thematisch, indem die lodernde Flammenmaske seiner Sol Iustitiae sich mit den weit aufgerissenen Augen verbindet. [Abb. 1,11 und 13] Wie Panofsky aufgefallen ist, taucht eine ähnliche Maske im ersten Blatt der dürerschen Bildreihe zur Apokalypse ${ }^{58}$ auf, die den Titel Johannes erblickt die sieben Leuchter [Abb. 14] trägt:

»Aber das Gesicht des Mannes ist von einem bebenden Strahlenhof umzogen, seine Augen brechen in Flammen aus, wie die des Menschsohns in der Vision der Sieben Leuchter, und seine Züge zeigen einen wild gewaltigen, doch kummervollen Ausdruck, seltsam verwandt dem seines phantastischen Reittiers. « ${ }^{59}$

Das Argument, dass es sich bei der Sol Iustitiae um Christus als Weltenrichter handle, gewinnt an Überzeugungskraft im Vergleich mit diesem im selben Jahr entstandenen Holzschnitt aus der Apokalypse. Auf beiden Blättern gehen die Feuerstrahlen ins gelockte Haar und die Linien des Strahlenkranzes über. Während bei Christus die aus zwei Teilen bestehende Maske, die die gerunzelte Stirn frei lässt, als Verlängerung der Augenbrauen und Wimpern erscheint und die beiden Flammen sich der Mandelform der Augen anpassen, [Abb. 13] herrschen in der Sol Iustitiae Kreis- und Kreuzformen vor. [Abb. 14] Einerseits bringen Kreislinien die schwarze Pupille, die Augenform, die Augenlider und die Formation der Flammen im Innern der Maske hervor, die auf diese Weise die Ausweitung der kreisrunden Augen aufnehmen. Anderseits ergeben die in drei Richtungen weisenden Flammenzungen ein Kreuz, ähnlich der Darstellungsweise des Kreuznimbus, die im Holzschnitt Virdungs $\mathrm{zu}$ finden ist. [Abb. 4 und 14] 


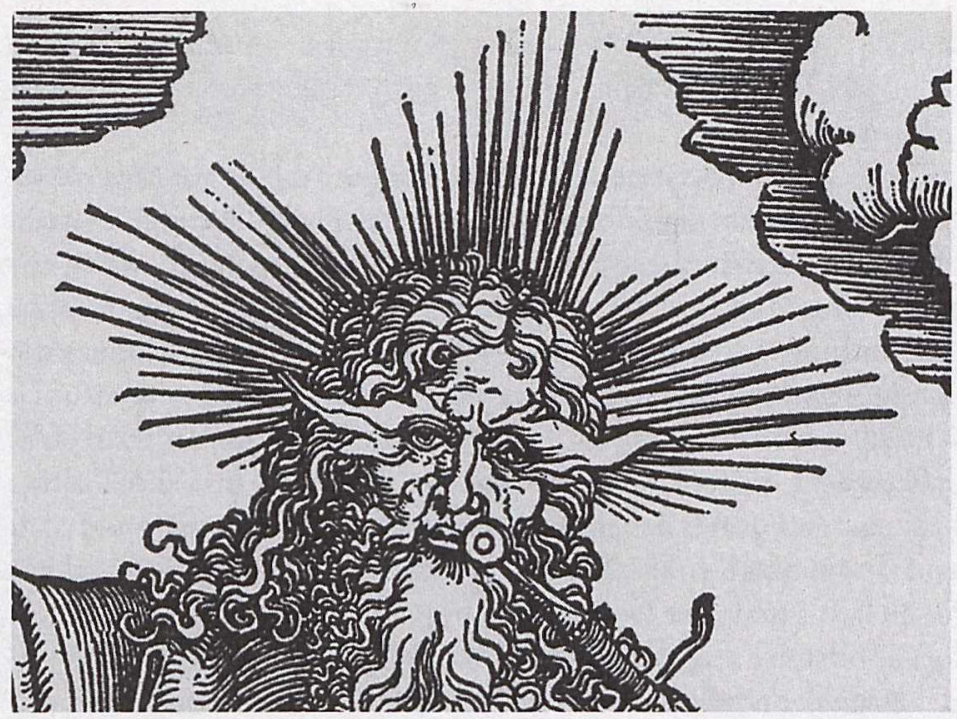

Nach Nikolaus von Kues liegt die Bedeutung des göttlichen Blicks aus dem Bild, wie sie Dürer darstellt, [Abb. 14] in seiner Partikularität und gleichzeitigen Allgegenwart. Jacques Lacan zu Folge ist die Funktion der Ikone ebenfalls darin zu sehen, dass »auch der Gott, den sie darstellt, sie anblickt « ${ }^{60}$ 14 Albrecht Dürer, Johannes erblickt die sieben Leuchter, 1498 (Detail), erstes Blatt der Illustration zur Apokalypse. Diesen omnipräsenten Blick erläutert von Kues anhand einer Vera Icon, die er zusammen mit seiner Schrift De Visione $D e i^{61}$ an seine Brüder geschickt hat. In dieser Schrift beschreibt er, dass der Betrachter vor dem Bild von jedem beliebigen Standpunkt aus von Christus angeblickt werde. Der Effekt, dass der inkarnierte göttliche Blick mit dem Beobachter mitwandert und ihn verfolgt, ob er nun links oder rechts vor dem Bild steht, entsteht dadurch, dass die Augen nicht nur aus dem Bild herausschauen, sondern wie bei dem apokalyptischen Weltenrichter Dürers [Abb.14] die gemalten Pupillen zwei unterschiedliche Punkte fixieren. Der daraus resultierende omnipräsente Blick Gottes ist bei Dürer zusätzlich an eine Maske gebunden, sodass das Blickhafte des allsehenden Gottes in dieser Darstellung des Weltenrichters noch verstärkt wird. Im Unterschied zum göttlichen Blick im apokalyptischen Holzschnitt Johannes erblickt die sieben Leuchter [Abb.13] richtet sich der Blick in der Sol Iustitiae jedoch nicht auf den Betrachter vor dem Bild, sondern fokussiert innerhalb des Bildraumes die rechte untere Ecke. [Abb. 14] Die Fixierung eines bestimmten Punktes ist deshalb relevant, weil sie das Hervortreten jenes Blickes verhindert, der den zugleich partikularen wie omnipräsenten Blick Gottes zu inkarnieren vermag. Stattdessen wird aufgrund der Neigung des Kopfes und der Lenkung des Blicks auf einen bestimmten Punkt exakt diejenige Position des Richters übernommen, wie sie sich auch in Cranachs Gemälde findet. [Abb. 10 und 11] Die Bilderfindung Dürers unterscheidet sich von der Darstellung des göttlichen Weltenrichters, indem sie, in der Terminologie Jacques Lacans, vom Blick zum Auge übergeht: Der Gerichtsraum verwandelt sich in dem Moment in einen Raum der Sichtbarkeit, in dem sich der Blick des Richters senkt und damit zum Auge wird. Das Auge, das wie in der zentralperspektivischen Konstruktion mittels Augpunkt über das Geschehen auf der Bühne zu herrschen 
glaubt, schmückt sich mit dem Blick, der sich zusammen mit dem Licht in den Darstellungen des christlichen Gottes wie auch des antiken Sol/Helios als allgegenwärtiger zeigt.

Der Betrachter befindet sich in Sol Iustitiae [Abb. 1] auf Augenhöhe mit dem gebückten Löwen, der seinen Kopf nach oben hebt. Dadurch entsteht der Eindruck, dass die männliche Figur eine erhöhte Beobachterposition einnimmt und auf diese Weise auf den Betrachter hinunter blicken könnte. Diese niedere Horizontlinie wird durch die Darstellung des nimbierten Mannes mit der Feuermaske verstärkt, dessen Kinn trotz der starken Senkung des Kopfes in Untersicht dargestellt ist. [Abb. 13] Auch im Gemälde Cranachs führen die steile perspektivische Konstruktion des Raumes einerseits und die Position Salomons im oberen Fünftel des Bildes anderseits zu einer Betonung des äuBerst hohen Standpunktes. [Abb. 12] Diese erhöhte Beobachterposition erklärt sich aus der älteren Praxis der Rechtssprechung, für die sie unabdingbar war, wie das Wort Lê oder Lee zeigt, das im Mittelhochdeutschen den Gerichtshügel bezeichnete. Denn der erhöhte Platz beim Hochgericht diente dem Zweck »der besseren Sichtbarkeit als Richtplatz «. ${ }^{62}$ Der landläufige Gebrauch des Wortes Lee wurde zudem oft mit dem ähnlich klingenden Wort Lêwe (Löwe) verwechselt, weshalb dieses Tier symbolisch für das Hochgericht stand. Zusammenfassend lässt sich daher sagen, dass nicht nur die Körperhaltung mit den überkreuzten Beinen, sondern auch die erhöhte Beobachterposition sowie die Fixierung der Augen auf einen bestimmten Punkt in einem rechtspraktischen und damit weder in einem christlichen noch in einem allegorischen Zusammenhang stehen. Die Schau des Richters, die Überblick über das ganze Verfahren verschafft, ist zugleich eine physische und metaphysische, da sie immer auch an die Stelle des göttlichen Blicks tritt. Dürer transzendiert mit Hilfe des Heiligenscheins dieses Sehen, das den Ausgangpunkt des juridischen Wahrheitsgeschehens bildet und fortan die neu auftauchende Tätigkeit des Abwägens und Urteilens übernehmen muss.

Kantorowicz konnte zeigen, wie, vermittelt durch den Heiligenschein, überindividuellen Ideen der Zeitaspekt eines Kontinuums verliehen werden konnte: »In der spätantiken Kunst wird ein Nimbus, der Vorläufer des Heiligenscheins, oft solchen Figuren verliehen, die eine überindividuelle Idee darstellen." Dieses Zeichen des Ranges sollte zum Ausdruck bringen, dass »die Figur in jeder Hinsicht ein Kontinuum repräsentierte, etwas Dauerndes, Immerwährendes jenseits der Zufälligkeiten der Zeit und des Verderbs «. ${ }^{63}$ Kantorowicz betont, dass die meist als Abstraktionen oder Personifikationen bezeichneten weiblichen Gestalten, beispielsweise römische Provinzen, dadurch ihren »überzeitlichen Charakter« innerhalb der kontinuierlich verlaufenden Zeit erhielten. Das Gleiche gilt »für Begriffe und Tugenden: Justitia oder Prudentia als antike Gottheiten sollten Kräfte darstellen, die ewig wirkten. ${ }^{64}$ Diese Zeitdimension führt zur Unterscheidung zwischen tempus, aeternitas und aevum, zwischen vergänglicher, irdischer Zeit, apokalyptischer Ewigkeit und immerwährender Dauer. Auf diese Weise artikuliert der Heiligenschein eine Änderung im Wesen der Zeit, er versetzt seinen Träger »scholastisch gesagt vom tempus zum aevum, aus der Zeit in die ewige Dauer, jedenfalls in ein Kontinuum einer Zeit ohne Ende ${ }^{65}$ 
Es soll nochmals in Erinnerung gerufen werden, dass es sich bei Sol Iustitiae [Abb. 1] weder um eine Allegorie der Justitia [Abb. 7] noch um das solare Sternzeichen des Löwen, [Abb.3] weder um Christus als apokalyptischen Weltenrichter [Abb. 6] oder den antiken Sonnengott Helios/Sol [Abb. 2,3 und 8] noch um einen Richter in Ausübung seines Amtes [Abb. 9 und 10] handelt. Vielmehr finden sich all diese Aspekte, von denen es einzelne Darstellungen gibt, bei Dürer in einem Bild, in einer nimbierten Figur mit Flammenblick vereinigt. Handelt es sich also in Anbetracht dieser Umstände um die Allegorie einer weltlichen Tätigkeit oder um ein göttliches numen mixtum? Diese Frage ist deshalb nicht nebensächlich, weil Allegorie und numen mixtum unterschiedliche Zeitkonzepte involvieren. Liest man die Sol Iustitiae typologisch, das heißt Sol als Präfiguration Christi, so bezieht sich die Darstellung auf ein heilsgeschichtliches Zeitverständnis und damit auf eine raum- und zeitenthobene zukünftige Ewigkeit. Liest man das Bild jedoch als Allegorie, steht dieses für eine immerwährende abstrakte Idee. Die Wirksamkeit und Macht des Bildes, als simultane Zusammenschau verschiedene Elemente, Vorstellungen und Ideen zu vereinen, spitzt sich in Sol Iustitiae noch weiter zu, indem dieses Bild zugleich numen mixtum und Allegorie ist. In der Überblendung von numen mixtum und Allegorie verleiht Sol Iustitiae sowohl der Tätigkeit des Urteilens ein allegorisches Gewicht, indem sie mit Löwe, Waage und Schwert ausgestattet ist, als auch dem Amt des Richters eine Dauer, indem der Heiligenschein sich mit Flammenmaske und Blickfokussierung verbindet. Neben dem omnipräsenten Auge des Richters in der erhöhten Beobachterposition erhält zudem der Löwe als Symbol der Wachsamkeit den Aspekt einer Dauer, da sich seine Augen selbst im Schlaf nicht schließen. Sol Iustitiae vereint diese beiden Konzepte ineinander, um das Amt des Richters typologisch zu wenden und ihm ein aevum wie auch die vordem dem Bereich des Göttlichen vorbehaltene Macht zu verleihen. Das jüngste Gericht wandelt sich in ein innerweltliches Geschehen, und das innerweltliche juridische Amt tritt in den Bereich des Heiligen (bzw. der antiken Götter, der Astrologie und der Apokalypse) ein. So verschränken sich auf genuin bildliche Weise Immanenz und Transzendenz. Bei der Schau des Richters handelt es sich folglich, wie Dürers Sol Iustitiae zeigt, um ein unverstelltes und direktes Sehen, das über das bloße und kontigente Vorhandensein hinausgeht. Als metaphysische Schau bestimmt sie stattdessen die Szene des Wahrheitsgeschehens und damit auch den Ort der Evidenz als Augenschein und Offenkundigsein. 


\section{Endnoten}

1 Vgl. Piyel Haldar, The Evidencer's Eye. Representations of truth in the laws of evidence, in: Law and Critique 2/2, 1991, S. 171-189.

2 Erwin Panofsky, Das Leben und die Kunst Albrecht Dürers, München 1977, S. 105.

3 Martin Wallraff, Christus verus sol. Sonnenverehrung und Christentum in der Spätantike, in: Jahrbuch für Antike und Christentum, Ergänzungsband 32, Münster 2001, S. 145. Uberdies wurde Sol oft mit einer Strahlenkrone geschmückt. Im Gegensatz zum Strahlenkranz auf Dürers Kupferstich umgeben dabei die Strahlen der Krone nicht den Kopf, sondern gehen von einem auf dem Kopf getragenen Reifen aus. Vgl. zu Sol und seiner christlicher Deutung sowie zu Nimbus, Strahlenkranz, Glorie und Mandorla ebd., S. 144-151.

4 Vgl. weiter zum Antikenbezug der Sol Iustitiae Erwin Panofsky, Dürers Stellung zur Antike, in: Jahrbuch für Kunstgeschichte, Bd.I, 1921/22, S. 43-92.

5 Friedrich Teja Bach, Struktur und Erscheinung. Untersuchungen zu Dürers graphischer Kunst, Berlin 1996.

6 Reiner Schoch, Die Sonne der Gerechtigkeit (Sol Iustitiae), in: Germanisches Nationalmuseum Nürnberg (Hg.), Albrecht Dürer. Das druckgraphische Werk, Bd. I, München 2001, S. $79 \mathrm{f}$.

$7 \mathrm{Zu}$ den künstlerischen Darstellungen Christi als Helios/Sol in der Spätantike vgl. Wallraff, Christus verus sol (Anm.3), S. 158-165.

8 Vgl. ebd., S. 174-195.

9 Franz Joseph Dölger, Sol salutis. Gebet und Gesang im christlichen Altertum. Mit besonderer Rücksicht auf die Ostung in Gebet und Liturgie, Münster 1972, S. 364-379; sowie Wallraff, Christus verus sol (Anm.3), S.110-125.

10 Teja Bach, Struktur und Erscheinung (Anm.5), S. 100.

11 Mal 3, 20, Vulgata, Mal 4,2.

12 Zitiert nach Panofsky, Das Leben und die Kunst Albrecht Dürers (Anm. 2), S. 106.

13 Elfriede Scheil, Albrecht Dürers Melencolia $\$$ I und die Gerechtigkeit, in: Zeitschrift für Kunstgeschichte 2, 2007, S.201-214, S. 203.

14 Zitiert nach Teja Bach, Struktur und Erscheinung (Anm. 5), S. 101.

15 Ebd., S.99.

16 Ebd.

17 Ebd., S.90-100.

18 Ernst H. Kantorowicz, Die zwei Körper des Königs. Eine Studie zur politischen Theologie des Mittelalters, Stuttgart, 1992, S.74. Horst Bredekamp hat gezeigt, dass die Souveränität als fiktive Person im juridischen Sinne einer Bildproduktion bedarf, da die Souveränität selbst nur als Bild zu denken ist: Horst Bredekamp, Politische Zeit. Die zwei Körper von Thomas Hobbes' 'Leviathan', in: Wolfgang Ernst, Cornelia Vismann (Hg.), Geschichtskörper. Zur Aktualität von Ernst H. Kantorowicz, München 1998, S.105-118.

19 Kantorowicz, Die zwei Körper des Königs (Anm. 18), S.78.

20 Friedrich Ohly, Halbbiblische und außerbiblische Typologie, in: ders., Schriften zur mittelalterlichen Bedeutungsforschung, Darmstadt 1977, S.361-400.

21 Ebd., S. 396.

22 Ebd.

23 Ebd.

24 Vgl. ausführlich zum bildlichen Zusammenfall von Johannes und Bacchus Erwin Panofsky, A Mythological Painting by Poussin in the Nationalmuseum Stockholm, Stockholm 1960, S. 36- 44 und Ohly, Halbbiblische und außerbiblische Typologie (Anm. 20), S. 396-400, Abb. 27-30.

25 Ebd., S. 397.

26 Ebd.

27 Panofsky, A Mythological Painting by Poussin in the Nationalmuseum Stockholm (Anm. 24), S. 40.

28 Vgl. Teja Bach, Struktur und Erscheinung (Anm. 5), S. 102; besonders Abb. 109 und Abb. 110.

29 Vgl. zur Ikonographie der Gerechtigkeit Rudolf Ott Kissel, Die Justitia. Reflexionen über ein Symbol und seine Darstellung in der bildenden Kunst, München 1984.

30 Kurt Rathe, Der Richter auf dem Fabeltier, in: Arpad Weixlgärtner, Leo Planiscig (Hg.), Festschrift für Julius Schlosser zum 60. Geburtstage, Zürich 1927, S. 187-208, S. 188.

31 Thomas Würtenberger, Recht und Gerechtigkeit in der Kunst Albrecht Dürers, in: Kunst und Recht. Festgabe für Hans Fehr, Bd. 1, Karlsruhe 1948, S. 221-235 und ders., Albrecht Dürer. Künstler-Recht-Gerechtigkeit, Frankfurt 1971.

32 Teja Bach, Struktur und Erscheinung (Anm. 5), S. 97. 
33 Schoch, Die Sonne der Gerechtigkeit (Sol Iustitiae) (Anm. 6), S. 80.

34 Panofsky, Das Leben und die Kunst Albrecht Dürers (Anm. 2), S. 105.

35 Teja Bach, Struktur und Erscheinung (Anm. 5), S. 101.

36 Schoch, Die Sonne der Gerechtigkeit (Sol Iustitiae) (Anm. 6), S. 80.

37 Panofsky, Das Leben und die Kunst Albrecht Dürers (Anm. 2), S. 105.

38 Susanne Lepsius, Wissen $=$ Entscheiden, Nichtwissen $=$ Nichtentscheiden? Zum Dilemma richterlicher Beweiserhebung im Spätmittelalter und in der frühen Neuzeit, in: Cornelia Vismann, Thomas Weitin (Hg.), Urteilen/Entscheiden, München 2006, S.119-142, S. 120.

39 Ebd., S. 121

40 Teja Bach, Struktur und Erscheinung (Anm. 5), S. 101

41 Vgl. zu diesem Bild Max J. Friedländer, Jakob Rosenberg, Die Gemälde von Lucas Cranach, Berlin 1932, S. 62; Kurt Simon; Abendländische Gerechtigkeitsbilder, Frankfurt a. M. 1948, S. 60 und S. 103; Rainer Michaelis, Deutsche Gemälde 14.-18.Jahrhundert, Berlin 1989, S.25; Gemäldegalerie Berlin: Gesamtverzeichnis, bearb.v. Henning Bock, Berlin 1996, S. 35.

42 Vital Huhn, Löwe und Hund als Symbol des Rechts, in: Mainfränkisches Jahrbuch für Geschichte und Kunst 7, 1955, S.1-63, S. 62.

43 Ebd., S. 58.

44 Ebd., S.11.

45 Rathe, Der Richter auf dem Fabeltier (Anm.30), S. 201.

46 1.Kön 3, 16-28.

47 Ebd.

48 Peter von Moos, Geschichte als Topik. Das rhetorische Exemplum von der Antike zur Neuzeit und die historiae im >Policraticus Johanns von Salisbury, Hildesheim 1988, S. 60.

49 Ebd., S. 62-63.

50 Kurth Gebien, Die Geschichte in Senecas philosophischen Schriften. Untersuchungen zum historischen Exempel in der Antike, Konstanz 1969, S. 40-42.

51 Karlheinz Stierle, Geschichte als Exemplum-Exemplum als Geschichte. Zur Pragmatik und Poetik narrativer Texte, in: Reinhart Koselleck, Wolf-Dieter Stempel (Hg.), Geschichte-Ereignis und Erzählung (Poetik und Hermeneutik 5), München 1973, S.347-375, S. 358.

52 Auch Markus Schürer betont die ausgeprägte Bildlichkeit des Exemplums. Markus Schürer, Das Exemplum oder die erzählte Institution. Studien zum Beispielgebrauch bei den Dominikanern und Franziskanern des 13. Jahrhunderts, Berlin 2005, S. 58-59.

53 John D. Lyons, Exemplum. The Rhetoric of Exemple in Early Modern France and Italy, Princeton 1989, S. $28-29$.

54 Hans-Christian von Herrmann, Das Archiv der Bühne. Eine Archäologie des Theaters und seiner Wissenschaft, München 2005, S. 62.

55 Cornelia Vismann, Das Drama des Entscheidens, in: dies., Weitin (Hg.), Urteilen/Entscheiden (Anm.38), S.91-100, S. 98.

56 Ebd., S.92.

57 Wallraff, Christus verus sol (Anm.3), S. 145.

58 Vgl. zum Gesamtkontext Peter Krüger, Dürers "Apokalypse«. Zur poetischen Struktur einer Bilderzählung der Renaissance, Wiesbaden 1996.

59 Panofsky, Das Leben und die Kunst Albrecht Dürers (Anm.2), S. 105.

60 Jacques Lacan, Die vier Grundbegriffe der Psychoanalyse. Das Seminar. Buch XI, Weinheim 1996, S. 120. Michel de Certeau weist strukturelle Gemeinsamkeiten zwischen Nikolas von Kues und Lacan nach. Michel Certeau, Nikolas von Kues, Das Geheimnis eines Blickes, in: Volker Bohn (Hg.), Bildlichkeit, Frankfurt a.M.1990, S.325-356, besonders S.345-348. Des Weiteren zur Unterscheidung von Auge und Blick Claudia Blümle, Anne von der Heiden, Blickzähmung und Augentäuschung. Zu Jacques Lacans Bildtheorie, Berlin/Zürich 2005.

61 Nicolaus Cusanus, Über das Sehen Gottes (de visione Dei) oder: Über das Bild (de icone), in: ders., Philosophische und theologische Schriften, übers. v. Anton Scharpff und Eberhard Döring, Wiesbaden 2005, S. 233-282. Vgl. zur bildtheoretischen Relevanz dieser Schrift Gottfried Boehm, Studien zur Perspektivität. Philosophie und Kunst in der Frühen Neuzeit, Heidelberg 1969, S. 137-171 sowie Holger Simon, Bildtheoretische Grundlagen des neuzeitlichen Bildes bei Nikolaus von Kues, in: Concilium medii aevi 7, 2004, S.45-76.

62 Huhn, Löwe und Hund als Symbol des Rechts (Anm.42), S. 60.

63 Kantorowicz, Die zwei Körper des Königs (Anm. 18), S. 97. 


\section{Endnoten/Abbildungsnachweis}

64 Ebd.

65 Ebd., S. 102

\section{Abbildungsnachweis}

1 Albrecht Dürer, Sol Iustitiae, um 1498/99, 7,9 ×10,7 cm, Kupferstich, The Metropolitan Museum, New York, in: Erwin Panofsky, Dürers Stellung zur Antike [1921/2], in: ders., Deutschsprachige Aufsätze, hg. v. Karen Michels, Martin Warnke, Bd. 1, Berlin 1998, S. 273, Abb. 17.

2 Helios, Metope vom Athena-Tempel in Troja, um 390 v. Chr., $85,8 \times 86,3 \mathrm{~cm}$, Marmor, Pergamonmuseum, Berlin, in: Erwin Panofsky, Dürers Stellung zur Antike [1921/2], in: ders., Deutschsprachige Aufsätze, hg.v. Karen Michels, Martin Warnke, Bd. 1, Berlin 1998, S. 275, Abb. 18.

3 Helios reitet auf dem Tierkreisbild des Löwen, Liber Bohan, Cod. Bodl. Or. 133, Bodleian Library, Oxford, aus: Friedrich Teja Bach, Struktur und Erscheinung. Untersuchungen zu Dürers graphischer Kunst, Berlin 1996, S. 102, Abb. 97.

4 Johannes Virdung, Christus und Sol, 1495 (Detail), Lateinischer Almanach für das Jahr 1495, Holzschnitt, in: Friedrich Teja Bach, Struktur und Erscheinung. Untersuchungen zu Dürers graphischer Kunst, Berlin 1996, S. 106, Abb. 98.

5 Doppelprofil von Konstantin und Sol invictus, Gold-Solidus, Bibliothèque Nationale, Paris, in: Ernst Kantorowicz, Die zwei Körper des Königs. Eine Studie zur politischen Theologie des Mittelalters, Stuttgart, 1992, Abb. 32 e.

6 Albrecht Dürer, Christus als Weltenrichter mit Schwert und Lilie (Die kleine Passion: Das Jüngste Gericht), 1509/11, 24×17 cm, Holzschnitt, in: Albrecht Dürer. Sämtliche Holtzschnitte, bearb.v. Monika Heffels, Ramerding 1981.

7 Albrecht Dürer, Justitia, 1495, 20,4 × 10,6 scm, Federzeichnung, vormals Museum Boymns-van-Beuningen, Rotterdam.

8 Sol, Kapitell der Planetengötter, um 1415, Portikus des Dogenpalastes in Venedig, in: Erwin Panofsky, Das Leben und die Kunst Albrecht Dürers, München 1977, S. 105.

9 Albrecht Dürer, Jüngling mit Waage und Stab, 1498, 24,2 ×20,8 cm, Federzeichnung, Eremitage, St. Petersburg, Inv.-Nr. 16, in: Ministerium für Kultur der DDR (Hg.), Deutsche Kunst der Dürerzeit, Dresden 1971, Kat. Nr. 148 [Katalog zur Ausstellung »Deutsche Kunst der Dürerzeit«, Albertinum, Dresden 1971].

10 Lucas Cranach d. Ä. und Werkstatt, Das Urteil Salomonis, um 1537 (Detail), 206,5×142 cm, Öl auf Pappelholz, Gemäldegalerie, Inv.-Nr. II.76, Preußischer Kulturbesitz, Staatliche Museen zu Berlin, Berlin, Foto: Jörg P. Anders.

11 Albrecht Dürer, Sol Iustitiae, um 1498/99, 7,9×10,7 cm, Kupferstich, The Metropolitan Museum, New York, in: Erwin Panofsky, Dürers Stellung zur Antike [1921/2], in: ders., Deutschsprachige Aufsätze, hg.v. Karen Michels, Martin Warnke, Bd.1, Berlin 1998, S.273, Abb. 17.

12 Lucas Cranach d. Ä. und Werkstatt, Das Urteil Salomonis, um 1537, 206,5×142 cm, Öl auf Pappelholz, Gemäldegalerie, Inv.-Nr. II.76, Preußischer Kulturbesitz, Staatliche Museen zu Berlin, Berlin, Foto: Jörg P. Anders.

13 Albrecht Dürer, Sol Iustitiae, um 1498/99 (Detail), 7,9 9 10,7 cm, Kupferstich, The Metropolitan Museum, New York, in: Erwin Panofsky, Dürers Stellung zur Antike [1921/2], in: ders., Deutschsprachige Aufsätze, hg.v. Karen Michels, Martin Warnke, Bd. 1, Berlin 1998, S.273, Abb. 17.

14 Albrecht Dürer, Johannes erblickt die sieben Leuchter, 1498 (Detail), erstes Blatt der Illustration zur Apokalypse, $39,2 \times 28,1 \mathrm{~cm}$, Druckgraphik, Staatliche Kunstsammlungen, Kupferstich-Kabinett, Dresden, in: Rudolf Chadabra, Dürers Apokalypse, Prag 1964. 
Der allgegenwärtige Blick des Richters. 